\title{
Investigation of HVOF thermal sprayed nanostructured WC-12Co mixed with Inconel-625 coatings for oil/gas applications
}

\author{
A. Al-Hamed ${ }^{1}$, H. Y. Al-Fadhli ${ }^{2}$, S. Al-Mutairi ${ }^{3}$, B. S. Yilbas ${ }^{4}$, \\ M. S. J. Hashmi ${ }^{1} \&$ J. Stokes ${ }^{1}$ \\ ${ }^{1}$ National Centre for Plasma Science and Technology, \\ School of Mechanical and Manufacturing Engineering, \\ Dublin City University, Ireland \\ ${ }^{2}$ Non-Metallic and Protective Coating Unit, \\ Consulting Services Department, Saudi Aramco Dhahran, Saudi Arabia \\ ${ }^{3}$ Research and Development Centre Unit, Saudi Aramco Dhahran, \\ Saudi Arabia \\ ${ }^{4}$ Mechanical Engineering Department, King Fahd University of \\ Petroleum and Minerals, Saudi Arabia
}

\begin{abstract}
Different machine parts in oil and gas industries suffer from erosion-corrosion degradations due to the impact of small solid particles entraining a liquid stream during transportation. To overcome such a tribological problem, the demand for WC-12Co and Inconel-625 HVOF thermal spray coatings is becoming more and more stringent. To date, the development of nanostructured WC-12Co feedstock materials have significantly improved the mechanical property performance of such coatings over conventional micro-structured coatings. This paper identifies the recent developments of WC-12Co nanostructured coatings and how they have performed when deposited using different thermal spray techniques. The research focuses also on the modification of WC-12Co by the addition of Inconel-625 against erosion-corrosion. The results demonstrate that the significant improvement in nanostructured WC-12Co coating performance can be achieved by utilizing proper controlling parameters for HVOF technique.

Keywords: nanostructure, HVOF, thermal spray, WC-Co, erosion, Inconel-625.
\end{abstract}




\section{Introduction}

One of the most common and unavoidable problems facing oil and gas industrial segments is the machine components degradation due to wear and corrosion. They have a huge effect on material losses, result in the destruction of components and transportation pipelines as shown in figure 1, and can cause health and environmental risks due to metal contamination. This can be considered from the point view of safety side. As a result, from economy side view the operating and maintenance costs increase. Recently, studies proved that the cost of material losses due to wear and corrosion denote in most of the developed industrial countries is approximately $4 \%$ of their gross internal product (GIP) (Jones and Llewellyn [1]). For example, in USA alone it was reported that the wear and corrosion of equipment's and mechanical components direct costs were about 22 billion Euros per year for spare parts alone (Scrivani et al. [2]). Additionally, one has to add an equal amount for indirect costs related to production stops, scrap creation and management, maintenance and personal. Therefore, wear and corrosion increase the operating and maintenance costs in various industrial applications. To overcome such tribological problem, the demand for thermal spray coatings is becoming more and more stringent.

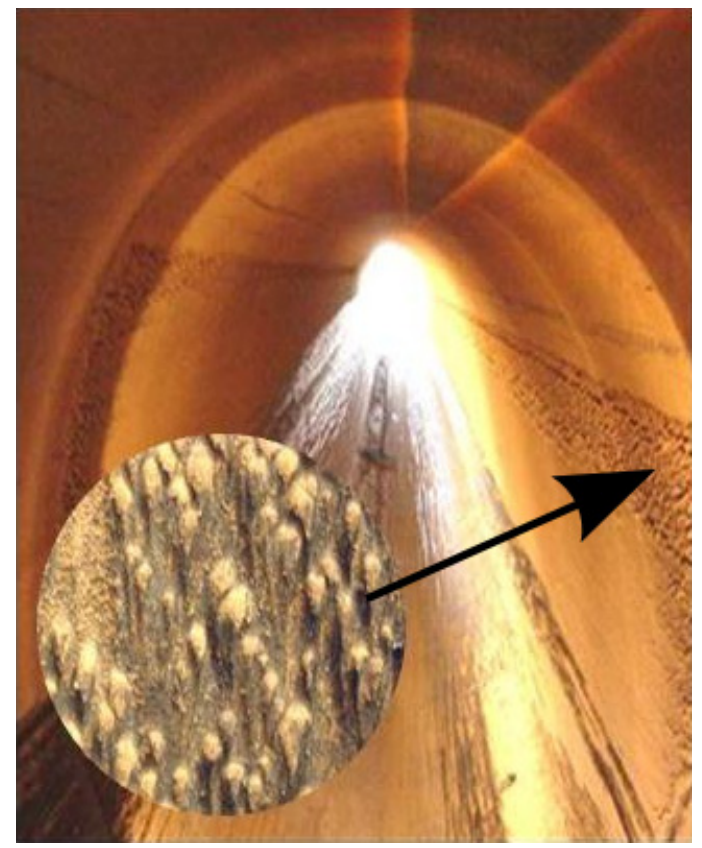

Figure 1: The internal wall degradation of a carbon steel oil sands tailings.

Recently, thermal spraying proved to be one of the widely recognized industrial solutions technologies to produce superior protective coatings. It is 
used in industrial applications requiring sliding, abrasion, and erosive wear resistance. However, the variety of applications ranges from aerospace landing gears to industrial oil pumps, to the blades of hydraulic turbines and piping valves. Novel research also demonstrates the thermal spray applications in magnetic and biomedical applications (Thayer [3], Kulkarni et al. [4]). The thermal spray technology has developed rapidly over the past twenty years besides the development of new feedstock materials and new progress requirements in industrial fields.

According to the energy source used, thermal spray can be divided into different techniques: plasma spray technique (atmospheric plasma APS, low pressure plasma LPPS, and vacuum plasma VPS), Flame spray technique, High velocity oxy/air-fuel technique (HVOF, HVAF), and Dentation gun technique (Pawlowski [5]). The high velocity oxygen fuel (HVOF) thermal spray technique compared to other spray techniques proved to be preferable depositing technique in industries specially, for temperature sensitive materials such as cermets due to its high flexibility (Vinayo et al. [6]). Additionally to that, several characteristics for this technique can be considered: high density and strong adhesion bond to substrates, lower porosity and oxidation, high compressive residual stresses to improve the coating life time and cost effectiveness (Schwetzke and Kreye [7]).

Now a day's environmental concerns are also being considered as an integral part of the design process. For achieving future economic competitiveness and lower environmental impact, our attention must therefore turn to processes that consume a minimum of resources. However, new modern developments in materials towards nanostructure size particles have improved the materials properties such as hardness, abrasive and sliding wear resistance. This is due to reduced inherent defects and dislocation between grain boundaries (Stokes [8], Qiao et al. [9]). Therefore, the deposition of nanostructured feedstock materials is leading to an engineered surface with excellent coating performance. However, in spite with these developments of nanocrystalline powders during the last ten years, HVOF practical applications in the repaired filed still present many research challenges such as detected failures, which occur in day to day operation, thus still require solutions. Specially, failure in complex surface geometries and very high shape accuracy produces conventional coatings obtained by HVOF which are not suitable compared to nanostructured coatings due to their high and nonuniform thickness or inconvenient surface roughness (Basak et al. [10]). Moreover, some engineering environments are challenging and require composite surface coating to achieve their goal (for example excellent wear and corrosion resistance). This combination of properties suggests at least two or more combinations of materials are needed.

In this research the development of Tungsten carbide in nanostructured and conventional size (WC-12Co) powders together with Inconel-625 micro-size powder were reviewed. All of the selected materials have various applications in many industrial sectors due to its superior wear and corrosion resistance respectively. However, the applications of these materials as conventional coating are common; but the applications of nanostructured coating have still not yet been widely understood. 


\section{HVOF WC-12Co nanostructure thermal spray coatings}

The HVOF thermal spraying process has commonly been accepted as the most effective and economic method for the developing nanostructured WC-12Co coatings. Particularly, with the multipart surface geometries and maximum shape accuracy, where conventional coating techniques are unsuitable as they impose high or non-uniform layer depths or inappropriate surface roughness (Yilbas and Arif [11], Thakure et al. [12]). An earlier study carried out by (Yao et al. [13]) established that nanostructured WC-Co materials had superior properties and a more homogeneous microstructure than those of conventional WC-Co composites. Nanostructured WC-Co also permitted optimization of specific properties without affecting others; higher toughness and ductility that could be reached without decreasing hardness and wear resistance. Skandan et al. [14] established a new class of High Velocity Oxy-Fuel thermal spray feedstock powders, which consist of a mixture of coarse (conventional) and fine (nanostructured) particles of WC-12Co. The results showed that the dissolution of the WC particles occurs in the Co matrix, led to a hardened matrix which also held the WC particles in position and improved the wear resistance.

Shipway et al. [15] investigated the performance of conventional and nanostructured WC-12Co materials in the form of coatings deposited by HVOF thermal spraying. The nanostructured powder demonstrated higher levels of decomposition through spraying to produce a coating for two different reasons. Firstly, the open porous structure of the powder particles themselves, led to overheating of the particles at higher temperatures during spraying which improved dissolution of WC into the liquid binder phase (first step of decomposition reaction). Secondly, the fine carbides in the nanostructured coatings produced higher surface area to volume ratio of the carbide grains in the powder particle, and therefore enhanced the kinetics of dissolution. Sliding wear examination of the coatings showed that material loss took place mainly due to carbide pull outs and by subsurface cracking. It was shown that subsurface cracking was encouraged by the existence of the extremely decomposed areas inside the microstructure which resulted in higher wear rates.

AC-HVAF spray coatings have been deposited from WC-10Co-4Cr powder in addition to a modified powder having different composition of WC-12Co nanostructured powder by (Liu et al. [16]). The results indicated that an addition of 15\% nano WC-12Co increased the coating hardness from 1677 to 1873 HV0.3. However, not only did the hardness improve by the addition of nanoWC-12Co powder but also the wear and erosion resistance of coated samples increased. They attributed this to the homogeneous distribution of nano-sized WC particles in the CoCr matrix. WC-12Co coatings deposited by HVOF spraying from conventional and nanostructured WC powder feedstock and laser treatment was also carried to minimize the coating porosity (Chen et al. [17]). The authors concluded that under conditions of micro-scale abrasion, the fine WC grain size in the nanostructured material caused a rapid pull-out of the hard phase and therefore to high wear rates. Furthermore, laser treatment led to a 
decrease in hardness of the coatings and to corresponding increase in abrasive wear rate.

Guilemany et al. [18] observed that bimodal (mixed nano and micro size) particles of WC-12Co HVOF thermal spraying had better abrasive and friction wear resistance compared to the nanostructured coating even though the latter had higher hardness value. Additionally, both nanostructured and bimodal coatings demonstrated superior corrosion resistance, better than the conventional coating for WC-12Co. According to authors, the bimodal powder also has the advantage of being less expensive than the nanostructured powder. Cho et al. [19] studied HVOF spray coating of both micro and nanostructured WC-12Co powders to develop the durability of sliding machine components. A Taguchi program was used to optimize HVOF spray parameters for both powders. The results indicated that hardness of nanostructured WC-12Co was lower than that of microstructured WC-12Co since the degree of hard WC decomposition was less hard W2C, W and graphite is larger due to the larger specific surface area. Moreover, the friction coefficient of nanostructured WC-12Co was lower than that of microstructure $\mathrm{WC}-12 \mathrm{Co}$ at both $25^{\circ} \mathrm{C}$ and $500{ }^{\circ} \mathrm{C}$, because of the extra decomposition of nanostructured WC-12Co.

In a comparative study carried out by (Ding et al. [20]) between conventional and submicron WC-12Co, a multimodal (mixed of both) WC-12Co coating deposited by HVOF was found to be denser with low porosity. In addition, the multimodal WC-12Co coating had shown excellent cavitation erosion resistance. However, the erosion rates were almost one third that of the conventional coating. Furthermore, dense nanostructure, high micro hardness and strong cohesive strength were obtained.

Skandan et al. [21] developed a unique feedstock material containing a mixture of coarse and fine particles of WC-12Co using HVOF coating. The powder mixture consisted of 70 vol.\% coarse grains. Sliding wear tests were conducted using a ball-on-disk tribometer at room temperature under various lubricated conditions. Results reported that the abrasion wear resistance is at least $50 \%$ better than that of conventional WC-12Co coating. They attributed the improvement of abrasive wear resistance in the multimodal coatings to a tough matrix and the absence of any decarburized phases. Another dominating factor was the reduction in average Co content and, hence, an increase in the volume fraction of hard, wear-resistant WC phase.

Three different commercially available WC-12Co powders (two conventional and a multimodal) were deposited by (Marple and Lima [22]) using different HVOF systems (JP5000, DJ2600, and DJ2700). The multimodal powder consisted of $50 \%$ coarse grain and the remaining was $50 \%$ nano-size. Their results noted that reasonably high values of deposition efficiency greater than $70 \%$ could be achieved under some conditions using the DJ system to deposit the multimodal feedstock. These deposition values were ominously above those obtained using conventional feedstock materials. They observed that the multimodal coatings tend to have a higher hardness than conventional coatings; however, in terms of abrasion resistance, there was little difference between the best-performing multimodal and conventional coatings. Another study of three 
commercial WC-12Co powders (conventional, multimodal, and nanostructured) was carried by (Dosta et al. [23]). They used HVOF with different spray conditions for each type of powders to form the coating. Nanostructured coatings reported improvement with new spray conditions and resulted in a very hard coating. However, better abrasive and wear resistance were shown by multimodal powder even though nanostructured coating has a high hardness but during spraying process the powder suffered from decarburization. In addition, they noticed that the reduction in the decomposition could be achieved by new spray conditions to improve the abrasive wear resistance of the nanostructured powder.

Wang et al. [24] studied the performance of abrasive and erosive wear of three different sizes (conventional, multimodal, and nanostructured) WC-12Co HVOF deposited coatings. This research observed that both multimodal and nanostructured ranked higher than conventional coating in terms of hardness and abrasive and erosive resistance. Moreover, nanostructured coating was found to have the best abrasive wear resistance among all and it was attributed to homogenous powder structure and smaller WC particle size.

Very high degree of decarburization of the WC particle was observed by A. Dent et al. [25] during HVOF spraying of nanostructured WC-12Co. As a result, the nanostructured WC-12Co coatings yielded lower wear resistance compared to the conventional coating, which was attributed to high porosity resulting from hollow sphere morphology in the WC powder size distribution. Moreover, it is reported that the abrasive wear resistance rate increased as the cobalt binder volume percentage decreased. Stainless steel (1Cr18Ni9Ti) was coated successfully by nanostructured WC-12Co powder using the HVOF by (Yin et al. [26]). The resulting nanostructured coating was proved to have better wear resistance compared with the conventional coating in sliding when using a Si3N4 ball at both ambient as well as elevated temperatures. They attributed this to the improved mechanical properties of the nanostructured coating because of the very fine microstructure. Moreover, the major differences in the wear mechanisms of both types of coatings gave rise to an improvement of toughness and strength as a result of small WC grain size. Basak et al. [27] showed that nanostructured WC-12Co coatings demonstrate superior wear resistance compared to micron sized ones. They further improved the coating by addition of small amount $\mathrm{Al}$ as alloying element. The elemental mapping explained that WC particles surrounded by Al distribution resulted in an increase of cohesion within the coating to form strong bonding and enhance the wear resistance.

\section{Modifications of WC-12Co by addition of Ni based alloys against erosion- corrosion}

Many components and machinery parts suffer from erosion-corrosion degradations due to the impact of small solid particles entrained a liquid stream. Normally, the coatings composition, microstructure, and the overall structural integrity play a big rule in the ability protection against erosion. Although WC12Co thermal spray coatings are effective in most of the applications against 
pure wear, as it is not well-matched for erosion-corrosion environment compared to the other coatings (Kumari et al. [28]). However, in environments being both erosive and corrosive the corrosion properties of the metallic binder must be considered. Pure cobalt binder suffers from corrosion when it exposed to corrosive environments like sea water. WC-12Co thermally spray coating have been the subjects of numbers erosion studies in coating research field (Kumari et al. [28], Liu et al. [29]). Liu et al. [29] reported that the addition of $15 \%$ of nano WC-12Co powder into WC-10Co-4Cr AC- HVAF improved the coating erosion resistance. The same result also obtained by (Wang and Yan [30]) noted that the WC-12Co coating with nanostructure feedstock (WC size 50-800nm) exhibited lowest erosion rate compared to other conventional and multimodal coatings.

It has been reported that erosion- corrosion properties of WC-12Co can be improved by addition of chromium based alloys for high temperature in energy industry applications especially power plant boilers or nickel based alloy for low temperature applications in oil and gas industries such as pipe and gate valves (Al-Taha et al. [31]). These two alloys improve the oxidation resistance of the WC-12Co coatings. In the oil and gas industry, Ni based alloy are widely used in applications that combined wear and oxidations. One the most commonly used HVOF Ni base alloy coatings powder is Inconel-625 (Diamalloy 1005), which offers high practically resistive surfaces to harsh corrosive environments with relatively low cost (Miguel et al. [32]). This material has owing several properties that make it superior when applied as a HVOF coating in order to protect components from erosion-corrosion attack (Al-Anazi et al. [33]). However, its high strength derived from the stiffening effect of molybdenum and niobium on its nickel-chromium matrix. Moreover, the combinations of elements also provide a wide range of superior resistance against aggressive environments. In addition, the high freedom of local attack (crevice, pitting) corrosion, wide range of temperatures and pressure, and high corrosion-fatigue is also a primary reasons for its wide acceptance in oil and chemical field (Specialmetales [35]).

Significant research studies wear carried out to examine Inconel-625 HVOF thermal sprayed coating (Al-Taha et al. [36], Liu et al. [37]) in different conditions. Al-Taha et al. [36] reported a significant improvement of the corrosion resistance of Inconel-625 with the addition of WC particles when applied onto steel 304 substrate surface using HVOF thermal spray. This research attributed the findings to the existence of WC particles, which modifies temperature rise and its gradient in the coating. Additionally, increasing the WC contents in the coating resulted with increase of Young' modulus, the fracture toughness, and the magnitude of the residual stress of the coating. The same finding was also observed in a case study for the same material carried by (Liu et al. [37]). Bakare et al. [38] investigated the passive films on wrought and HVOF thermally sprayed Inconel- 625 using XPS analyses. They indicated that the superior corrosion resistance of Inconel-625 is due to formation of Mo, Cr, and Nb oxides.

The erosion-corrosion behavior of HVOF thermally sprayed Inconel 625 coating on different metallic surfaces was investigated by (Al-Fadhli et al. [39]).The coating exhibited excellent erosion-corrosion resistance, as it was not 
highly affected by the type of substrate material. Furthermore, (Li and Li [40]) indicated that the adhesive strength of the coating increased from $40 \mathrm{MPa}$ to 56 $\mathrm{MPa}$ when a bond coat of about $50 \mu \mathrm{m}$ thickness was introduced between the coating NiCrBSi and the mild steel substrate. Also, the bond strength increased to $65 \mathrm{MPa}$ by applying a WC-Co interlayer bond coat to the NiCrBSi-40wt\% WC-Co.

Further efforts to improve the erosion-corrosion behavior of Inconel-625 HVOF thermal sprayed coating were carried by a number of researches using laser surface melting (LSM) treatment (Ahmed and Bakare [41], Liu et al. [42]). For example, both (Ahmed [41] and Al-Taha [36]) observed that laser surface melting of HVOF of Inconel 625 largely eliminates porosity and localized regions as well as general homogenization and results in improvement of erosion-corrosion and wear resistance of the coating. However, some LSM studies (Bakare et al. [38], Liu et al. [42]) had an insignificant effect on the coating performance due to overlapping tracks which result in corrosion resistance degradations.

\section{Conclusions}

In general, surveys show that deposition of WC-12Co nanostructure by HVOF has shown superior resistance to pure wear compared to the conventional microstructural types. However, with proper control of the coating parameters and addition of Inconel-625 enhance the erosion resistance of the coating against erosion-corrosion. This can mostly be attributed to the passive films formed by Inconel-625 due to the combinations of elements. The future research will involve blending WC-12Co nanostructure powders with Inconel-625, depositing them and assessing the coating mechanical, wear and corrosion properties, to identify an optimum HVOF coated blend to prevent deterioration in oil/gas applications.

\section{Acknowledgements}

The research was sustained by Funding from Dublin City University (DCU) and collaboration with King Fahad University of Petroleum and Mineral (KFUPM) and Saudi Aramco Company.

\section{References}

[1] Jones M. \& Llewellyn R., Erosion-corrosion assessment of materials for use in the resources industry. Wear, (267), pp. 2003-2009, 2009.

[2] Scrivani A., Lanelli S., Rossi A., Groppetti R. \& Casadei F., A contribution to the surface analysis and characterization of HVOF coatings for petrochemical application. Wear, (250), pp. 107-113, 2001.

[3] Thayer A., Nanomaterial. Chemical and engineering news, 35(81), pp. 1522, 2003. 
[4] Kulkarni A., Gutleber J., Sampath S., Goland A., Lindquist W., Herman H., Allen A. \& Dowd B., Studies of the microstructure and properties of dense ceramic coatings produced by high-velocity oxygen-fuel combustion spraying. Material Science Engineering, 369, pp.124-127, 2004.

[5] Pawlowski L., The Science and Engineering of Thermal Spray Coatings, John Wiley \& Sons: England, pp. 60-67, 2008.

[6] Vinayo M., Kassabji F., Guyonnet J. \& Fauchais P., Plasma sprayed WCCo coatings: Influence of spray conditions (atmospheric and low pressure plasma spraying) on the crystal structure, porosity, and hardness. Vac Sci Technol A, pp. 2483-9, 1985.

[7] Schwetzke R. \& Kreye H., Microstructure and properties of tungsten carbide coatings sprayed with various high-velocity oxygen fuel spray systems. Proc. of the 15th International Thermal Spray Conference, C. Coddet, Ed., ASM International, Materials Park, OH, pp. 433-9, 1999.

[8] Stokes J., Theory and Application of Sulzer Metco (HVOF) Thermal Spray, Ireland, 2008.

[9] Qiao Y., Fischer T. \& Dent A., The effects of fuel chemistry and feedstock powder structure on the mechanical and tribological properties of HVOF thermal-sprayed WC-Co coatings with very fine structures. Surface and Coating Technology, 172, pp. 24-41, 2003.

[10] Basak A., Matteazzi P., Vardavoulias M. \& Celis J., Corrosion-wear behaviour of thermal sprayed nanostructured FeCu/WC-Co coatings. Wear, 261, pp. 1042-1050, 2006.

[11] Yilbas B. \& Arif A., Residual stress analysis for HVOF Diamalloy 1005 coating on Ti-6Al-4V alloy. Surface and Coatings Technology, 202(3), pp. 559-568, 2007.

[12] Thakure L., Arora N., Jayaganthan R. \& Sood R., An investigation on erosion behavior of HVOF sprayed WC-CoCr coatings. Applied Surface Science, 285, pp. 1225-1234, 2011.

[13] Yao Z, Stiglich J. \& Sudarshan TS. Nanosized WC-Co holds promise for the future. Metal Powder Report, 53(3), pp. 26-33. 1998.

[14] Skandan G., Yao R., Sadangi R., Kear B., Qiao Y., Liu L. \& Fischer T., Multimodal Coatings: a new concept in thermal spraying. Thermal Spray Technology, 9(3), pp. 329-331, 2000.

[15] Shipway P., McCartney D. \& Sudaprasert T., Sliding wear behavior of conventional and nanostructured HVOF sprayed WC-Co coatings. Wear, 259(7), pp. 820-827, 2005.

[16] Liu S., Zheng X. \& Geng G., Influence of nano-WC-12Co powder addition in WC-10Co-4Cr AC-HVAF sprayed coatings on wear and erosion behavior. Wear, 269(5), pp. 362-367, 2010.

[17] Chen H., Xu C., Zhou Q., Hutchings I., Shipway P. \& Liu J., Micro-scale abrasive wear behavior of HVOF sprayed and laser-remelted conventional and nanostructured WC-Co coatings. Wear, 258(1), pp. 333-338, 2005.

[18] Guilemany J., Dosta S. \& Miguel J., The enhancement of the properties of WC-Co HVOF coatings through the use of nanostructured and 
microstructured feedstock powders. Surface and Coatings Technology, 201(3), pp.1180-1190, 2006.

[19] Cho T., Yoon J., Kim K., Song K., Joo Y., Fang W., Zhang S. \& Youn S., Chun H., Hwang S., A study on HVOF coatings of micron and nano WCCo powders. Surface and Coatings Technology, 202(22), pp. 5556-5559, 2008.

[20] Ding Z., Chen W. \& Wang O., Friction and wear characteristics of multimodal WC-12Co coatings deposited by HVOF. Transactions of Nonferrous Metals Society of China, pp. 2231-2236, 2011.

[21] Skandan G., Yao R., Kear K., Qiao Y., Liu L. \& Fischer T., Multimodal powders: a new class of feedstock material for thermal spraying of hard coatings. Scripta Materialia, 44(8), pp. 1699-1702, 2001.

[22] Marple B. \& Lima M., Process temperature/velocity-hardness-wear relationships for high-velocity oxyfuel sprayed nanostructured and conventional cermet coatings. Thermal Spray Technology, 14(1), pp. 67-76, 2005.

[23] Dosta S., Miguel J. \& Guilemany J., Nanostructured cermet coatings with enhanced properties produced by HVOF thermal spray. Materials Science Forum, pp. 1024-1028, 2008.

[24] Wang Q, Chen Z., Ding Z. \& Liu Z., Performance study of abrasive wear and erosive wear of WC-12Co coatings Sprayed by HVOF. International Nanoelectronics Conference, 2nd IEEE International, 2008.

[25] Dent A., Depalo S. \& Sampath S., Examination of the wear properties of HVOF sprayed nanostructured and conventional WC-Co cermets with different binder phase contents. Thermal Spray Technology, 11(4), pp. 551558, 2002.

[26] Yin B., Zhou H., Yi D., Chen J. \& Yan F., Microsliding wear behavior of HVOF sprayed conventional and nanostructured WC-12Co coatings at elevated temperatures, Surface Engineering, 26(6), pp. 469-477, 2012.

[27] Basak A., Celies J., Vardavoulias M. \& Effect of nanostructuring and Al alloying on friction and wear behavior of thermal sprayed WC-Co coatings, Surface and Coatings Technology, 206, pp. 3508-3516, 2012.

[28] Kumari K., Anand K., Bellacci M. \& Giannozzi M., Effect of microstructure on abrasive wear behavior of thermally sprayed WC-10Co4Cr coatings. Wear, 268 (11-12), pp. 1309-1319, 2010.

[29] Liu S.L., Zheng X.P. \& Geng G.Q., Influence of nano-WC-12Co powder addition in WC-10Co-4Cr AC-HVAF sprayed coatings on wear and erosion behavior, Wear, 269 (5-6), pp. 362-367, 2010.

[30] Wang Y. \& Yan, The effect of $\mathrm{CeO} 2$ on the erosion and abrasive wear of thermal sprayed FeAl intermetallic alloy coatings. Wear, 261 (11-12), pp. 1201-1207, 2006.

[31] Al-Taha Z., Hashmi M. \& Yilbas B., Effect of WC on the residual stress in the laser treated HVOF coating. Materials Processing Technology, pp. 3172-3181, 2009. 
[32] Miguel J., Guilemany J. \& Vizcaino S, Tribological study of NiCrBSi coating obtained by different processes. Tribology International 36(3), pp. 181-187, 2003.

[33] Al-Anazi, D., Hashmi, M. \& Yilbas, B., High-velocity oxy-fuel coating of AMDRY 9954 on to Ti-6Al-4V alloy: Fracture toughness measurement. Engineering Manufacture, 221(4), pp. 617-623, 2007.

[34] Yilbas B., Khalid M. \& Abdul-Aleem B., Corrosion behavior of HVOF coated sheets. Thermal Spray Technology, 12(4), pp. 572-575, 2003.

[35] Specialmetales, www.specialmetales.com

[36] Al-Taha Z., Hashmi M. \& Yilbas B., Laser treatment of HVOF coating: model study and characterization. Mechanical Science and Technology, 21(10), pp. 1439-1444, 2007.

[37] Liu Z., Cabero J., Niang S. \& Al-Taha Z., Improving corrosion and wear performance of HVOF-sprayed Inconel 625 and WC-Inconel 625 coatings by high power diode laser treatments. Surface Coating Technology, 201, pp. 7149-7158, 2007.

[38] Bakare M., Voisey K., Roe M. \& McCartney D., X-ray photoelectron spectroscopy study of the passive films formed on thermally sprayed and wrought Inconel 625. Applied Surface Science, 257(3), pp. 768-794, 2010.

[39] Al-Fadhli H., Stokes J., Hashmi M. \& Yilbas B., HVOF Coating of welded surfaces: corrosion-fatigue behavior of stainless steel coated with Inconel625 alloy. Surface Coatings Technology, 200(20-21), pp. 5782-5788, 2006.

[40] Li C. \& Li H., Effect of WC-Co addition on the adhesion of HVOF Nibased coatings. Proc. of the $21^{\text {st }}$ Century, ASM International, Materials Park, OH, pp. 723-728, 1998.

[41] Ahmed N. \& Bakare M., The effects of microstructural features on the performance gap in corrosion resistance between bulk and HVOF sprayed Inconel 625. Surface and Coating Technology, 204 (14), pp. 2294-2310, 2010.

[42] Liu Z., Chong P., Skeldon P., Hilton P., Spencer J. \& Quayle B., Fundamental understanding of the corrosion performance of laser-melted metallic alloys. Surface and Coating Technology, 200, pp. 5514-5525, 2006. 